\title{
Trabalho social com famílias na Política de Assistência Social: elementos para sua reconstrução em bases críticas
}

\author{
Social work with families in Assistance Policy: evidence for its reconstruction at the critical \\ bases
}

\author{
Solange Maria Teixeira*
}

\begin{abstract}
Resumo:
A família assume a centralidade nas políticas sociais, em especial, na assistência social, o que tem reatualizado as demandas de trabalho socioeducativo com grupos de famílias. O objetivo deste artigo é retratar a trajetória histórica, com ênfase na contemporaneidade, do modo de abordar e trabalhar com famílias na assistência social, além de oferecer contribuições para repensá-las em bases críticas.
\end{abstract}

Palavras-chave: Serviço Social. Família. Política de Assistência Social. Trabalho Social com famílias.

\begin{abstract}
:
The family assumes centrality in social policies, especially in social assistance, which has revitalized the demands of social educational work with groups of families. The aim of this paper is to portray the history of this program with an emphasis on the present, to show how to approach and work with families on social assistance, and to provide ideas on how to rethink them at the critical bases.
\end{abstract}

Keywords: Social Service. Family. Social Policy. Social Work with Families.

\section{Introdução}

A assistência social no Brasil, desde a Constituição Federal de 1988, fundamenta-se em um novo paradigma, o do direito social, à medida que passa a ser definida como política pública; logo, política de Estado independentemente de governos específicos. As legislações que a regulamentaram posteriormente, como a LOAS (1993), PNAS (BRASIL, 2004) e NOB/SUAS (BRASIL, 2005), materializam essa nova dimensão e promovem reordenamentos institucionais; definem responsabilidades; hierarquizam e territorializam

\footnotetext{
UFPI. Pós-Doutorado em Serviço Social e Doutora em Política Pública. E-mail: solangemteixeira@hotmail.com.
} 
a proteção social oferecida; definem formas de financiamentos, elementos de pactuação e de controle social.

Para Sposati (2004), a assistência social definida na legislação é uma das ferramentas para ativar um novo contrato social na direção da inclusão dos excluídos, parte fundamental do sistema de proteção social brasileiro. "Não há dúvida que a assistência social opera na dinâmica da extensão da agenda pública para os novos direitos sociais, inclusive, não contributivos" (SPOSATI, 2004, p. 39). Permite ampliar o alcance da cidadania, ainda que em uma sociedade de desigualdades, rompendo com a tendência de inclusão no sistema de proteção social via cidadania regulada. Santos (1987) destaca que a cidadania regulada é a denominação do arranjo de proteção social que outorga o estatuto da cidadania apenas aos membros da comunidade nacional, localizados em ocupações reguladas pelos preceitos legais, como a legislação trabalhista sendo, portanto, estratificada por ocupação. Os usuários da assistência social eram considerados subcidadãos - por destinar-se aos sem trabalho - e todos aqueles cujo trabalho a lei desconhecia.

O novo desenho da Política de Assistência Social busca romper com a tradição de atendimentos pontuais, dispersos, descontínuos e fragmentados, voltados para situações limites extremas, assumindo uma dimensão preventiva, em nível de atenção básica, além daquela dirigida para situações de média e alta complexidade, quando o risco ou violação de direitos já ocorreu. Há, entre seus princípios estruturadores, a matricialidade sociofamiliar como antídoto à fragmentação dos atendimentos, como sujeito à proteção de uma rede de serviços de suporte à família.

Vale ressaltar que a PNAS (BRASIL, 2004) e SUAS (BRASIL, 2005) ao adotarem o princípio da matricialidade sociofamiliar não conseguem superar a tendência familista ${ }^{1}$ da política social brasileira, em especial da assistência social, pois, se por um lado o termo significa que a família é a matriz para concepção e implementação dos benefícios, programas e projetos, que em hipótese pode romper a fragmentação do atendimento, por outro, toma a família como instância primeira ou núcleo básico da proteção social aos

\footnotetext{
${ }^{1}$ Como destaca Esping-Andersen (1999), o "familismo" ou tendência familista da política social não pode ser confundido com pró-família, mas uma perspectiva de maior responsabilização da família pelo bem-estar de seus membros, incentivado pelas políticas públicas, seja pelo seu subdesenvolvimento em serviços de apoio à família, por benefícios poucos generosos ou pelo princípio da subsidiaridade do Estado, recaindo sobre a família a responsabilidade pelos serviços de proteção social.
} 
seus membros, devendo ser apoiada para exercer em seu próprio domínio interno as funções de proteção social, portanto, continua-se a responsabilizar a família, em especial às mulheres, pelos cuidados e outras tarefas de reprodução social.

Todavia, as mudanças legais criam expectativas de mudanças estruturais na assistência social no Brasil; mas elas promoveram reordenamentos institucionais e orientações técnicas capazes de romper com a tradição histórica da assistência social, especialmente do trabalho social com famílias de caráter normativo, disciplinador, conservador e moralizante?

O objetivo deste artigo é retratar as formas de abordar e trabalhar com a família na assistência social, em especial na contemporaneidade, a partir do novo reordenamento legal, destacando limites e possibilidades destes, além de oferecer pistas para a sua reconstrução em bases críticas.

\section{A tradição histórica do trabalho social com famílias na assistência social}

O modo como a família é incorporada à política pública reflete na organização dos serviços e na proposição e organização do trabalho com as famílias no cotidiano dos serviços, programas e projetos (MIOTO, 2006).

Em virtude da forma de organização da assistência social, historicamente marcada por atendimentos segmentados por categorias, fragmentados em problemáticas, os serviços foram dispostos a partir de "indivíduos-problemas" e "situações específicas", como, por exemplo, trabalho infantil, abandono, exploração sexual, delinquência, dentre outras, não contemplando a família como uma totalidade.

Em relação às famílias pobres, subjacentes à lógica da assistência social, estava a ideia de que a família é constitutiva do problema social, e de que seus responsáveis não tinham capacidade de educar as crianças, proteger seus membros da marginalidade, da promiscuidade e dos vícios.

São, assim, consideradas incapazes, devido a sua debilidade, desagregação conjugal, à pobreza, dentre outros, cabendo ao Estado, nessas situações limites, livrá-las dos riscos, por via da institucionalização, com o afastamento do ambiente familiar, assim "legitimando as internações, as reclusões, os asilamentos, tomadas também como medidas de segurança para a família e sociedade" (FONTENELE, 2007, p. 49). 
As medidas e políticas sociais que afetavam a família, geralmente, reproduziam concepções idealizadas de família-padrão, "normal" e os papéis clássicos entre seus membros, discriminando as outras organizações familiares e mantendo a associação família irregular/pobreza.

A família "normal" - a nuclear tradicional, tomada como padrão - ou as famílias eram definidas segundo a presença de um casal heterossexual e sua prole, concepção difundida por várias disciplinas científicas, como, por exemplo, a Psicologia e os Terapeutas Familiares, Psicanálise, dentre outras. Para estas disciplinas, a maior parte das outras formas de composição familiar ou era encarada como patológica, incompleta, insuficiente, ou era simplesmente invisível.

Mioto (2004a; 2006) sintetiza o trabalho social com família baseado em: a) Concepções estereotipadas de famílias e papéis familiares, centrados na noção de família padrão e as demais como "desestruturadas', com expectativas das clássicas funções alicerçadas nos papéis atribuídos por sexo e lugar nos espaços público e privado; b) Prevalência de propostas residuais, dirigindo-se a determinados problemas, segmentados e fragmentados da totalidade social, tomados como "desviantes", "patológicos" e sujeitos ao trabalho psicossocial individualizante e terapêutico, para cujo diagnóstico e solução envolve-se a família, responsabilizada pelo fracasso na socialização, educação e cuidados de seus membros; c) Focalização nas famílias em situação-limite, em especial nas "mais derrotadas", "incapazes", "fracassadas", e não em situações cotidianas da vida familiar, com ações preventivas e na oferta de serviços que deem sustentabilidade às famílias.

Nessa perspectiva, o trabalho social com famílias dirigiu-se às chamadas famílias "desestruturadas", "incapazes", trabalhando com o paradigma da patologia social e com os recursos terapêuticos do trabalho psicossocial individualizante.

As práticas socioeducativas dirigidas aos grupos de família dos segmentos atendidos, quando não institucionalizados ou retirados do convívio familiar, eram desenvolvidas em uma dimensão normatizadora e disciplinadora (dimensão moral e doméstica, geralmente dirigidas às mulheres).

Nesses casos, como destaca Mioto (2006), a família é tomada como parte do problema cuja solução e dificuldades estavam centradas nela própria; e assim fortalece- 
se, direita ou indiretamente, uma visão da família como produtora de patologias,buscando sua pacificação artificial.

Sem dúvida, a assistência social historicamente quando trabalhava com famílias pobres era no sentido de tomá-la como irregulares, culpadas e incapazes. Os serviços de inclusão eram quase inexistentes, bem como os benefícios eram poucos generosos, cabendo às famílias realizarem os serviços de assistência, cuidados, educação e socialização de seus membros, perdendo a guarda definitiva ou temporária destes quando não conseguiam evitar a "situação-problema". Essa tendência não se restringiu à assistência social antes de 1988, sendo constantemente atualizada, mesmo com as tentativas de mudanças nas últimas décadas.

\section{A Política de Assistência Social pós-Constituição de 1988: inovações e limites}

Atualmente, a assistência social vem passando por mudanças em todo o mundo, por afastar-se da tradição histórica do assistencialismo, da distribuição de cestas de alimentos para a transferência monetária, dos atendimentos emergenciais para ações sistemáticas, planejadas, contínuas e, como destaca Fulgheraiter (apud MIOTO, 2002), incorporou a dimensão preventiva dessas situações, de promoção do bem-estar e da qualidade de vida; além disso, ampliou seu escopo, visando atingir e trabalhar estados de sofrimento, exclusão, vulnerabilidade, discriminações, dentre outros.

Essa tendência é verificada no Brasil, em que a própria direção da política de Assistência Social tem-se alterado na contemporaneidade, buscando superar as visões de pobreza restrita a ausência ou precariedade de renda, e os atendimentos parcializados, segmentados e isolados, dirigindo-se à família e às suas necessidades. Há expectativas quanto à redefinição do trabalho social com famílias, com práticas socioeducativas alternativas, dirigidas para a autonomia e protagonismo das famílias.

As novas regras das legislações atuais da assistência social, dentre elas a PNAS e SUAS, provocam, de maneira geral, expectativas e demandas, por uma nova lógica de gestão, por mais recursos, por melhores condições de trabalho, mais profissionais contratados, capacitação, novas estruturas físicas, com a implantação de Centros de Referência de Assistência Social (CRAS), dentre outros. Outra expectativa está relacionada 
às mudanças nos processos de trabalhos, no desenvolvimento de novas competências e saberes, dentre elas o trabalho social com famílias.

\section{Trabalho social com famílias na proteção social básica}

O pressuposto ou fundamento do trabalho social com famílias, previsto na legislação da assistência social, como PNAS, SUAS, e, em especial, no principal programa desenvolvido nos Centros de Referência de Assistência Social (CRAS), Programas de Atenção Integral à Família (PAIF) é a concepção de família.

Quanto ao arcabouço conceitual da PNAS e SUAS, é visível, ao lado da modernização conceitual, no que diz respeito à concepção, composição e estruturação das famílias, o conservadorismo nas expectativas em relação às funções da família.

A PNAS (BRASIL, 2004, p. 28), tendo como referência o PAIF, destaca a concepção de família que o rege e à política, definindo-a do seguinte modo: "estamos diante de uma família, quando encontramos um conjunto de pessoas que se acham unidas por laços consanguíneos, afetivos e/ou de solidariedade"; portanto, partem de uma visão ampliada de família. Reconhece, ainda, que "não existe família enquanto modelo idealizado, e sim família resultante de uma pluralidade de arranjos e re-arranjos estabelecidos pelos integrantes dessa família".

Pode-se, então, afirmar que a política (e o Estado) assume uma posição que contribui para enfraquecer os estigmas associados à maternidade sem casamento, às famílias reconstituídas, às vezes, sem vínculos formais, às uniões consensuais, ao divórcio, assumindo todos esses grupos como unidade familiar e sujeitos à proteção social da assistência social, desde que dela necessitem.

Mas também se observa no desenho da política que a proteção oferecida exige contrapartidas; qual seja, que a família cumpra suas clássicas funções, sobrecarregando de responsabilizações à família e reproduzindo estereótipos acerca dos papéis familiares.

Isso porque, apesar de a PNAS reconhecer teoricamente e assim superar o modelo único baseado na família nuclear, ainda tem expectativas quanto às funções básicas da família desse modelo: "prover a proteção e a socialização dos seus membros, constituirse como referências morais, de vínculos afetivos e sociais; de identidade grupal, além de 
mediadora das relações dos seus membros com outras instituições sociais e com o Estado" (BRASIL, 2004, p. 35).

Embora essa concepção supere o conceito de família como unidade econômica (NOB/SUAS), mera referência de cálculo de rendimento per capita, e parta de uma visão ampliada de família, com formatos plurais, historicamente situada, e inclua a ideia de que esta deve ser apoiada, o objetivo, na verdade, é apoiar para que esta possa desempenhar o seu papel de sustento, na guarda, na socialização e na educação de suas crianças, adolescentes, no cuidado de seus idosos e portadores de deficiência. Logo, a noção de matricialidade sociofamiliar desvela seu verdadeiro significado, de ampliar e contar mediante estratégias de racionalização e orientação - com a proteção da família, reforçando a tendência familista da política social brasileira.

Assim, apesar de o reconhecimento da pluralidade de formas familiares, as homogeneízam em suas funções, papéis e relações internas, trata-a, a priori, como o lócus da felicidade, do refúgio da vida desumana do mercado, da proteção social.

O PAIF tem como pressuposto que a família é o núcleo básico de afetividade, acolhida, convívio, autonomia, sustentabilidade e referência no processo de desenvolvimento e reconhecimento do cidadão; e, de outro, que o Estado tem o dever de prover proteção social respeitada a autonomia dos arranjos familiares (BRASIL, 2006, p. 28). Portanto, reconhece os diferentes arranjos familiares e o papel integrador da família, apostando nessa capacidade das famílias para maximizar a proteção oferecida.

É essa ambiguidade de reforço das funções protetivas da família de um lado; e, de outro, como alvo de proteção social que denota a dimensão da parceria público/privada na proteção social, e sua dimensão estratégica em contexto de redução de gastos sociais, posto que se pode contar com a parceria da família para potencializar a proteção social oferecida, mesmo quando não ocorre em quantidade nem qualidade suficiente para suprir todas as atenções necessárias e demandadas.

Essa concepção de família direciona e tem impactos nas indicações e recomendações do Ministério do Desenvolvimento e Combate à Fome (MDS) para o trabalho social com famílias a ser desenvolvido na proteção social básica, sendo seu lócus principal os CRAS. O trabalho socioassistencial desenvolvido nos CRAS, que se relaciona a toda a ação de provimento e de sustentação para o atendimento das famílias usuárias, é 
acompanhado das ações de acolhimento, escuta qualificada e encaminhamento, e também de ações socioeducativas, que, segundo Mioto (2004b, p.10), "estão relacionadas àquelas que, através da informação, da reflexão, ou mesmo da relação, visam provocar mudanças (valores, modo de vida)".

Esse trabalho, denominado de "núcleos socioeducativos" com famílias ou seus representantes, está previsto e é financiado pelo piso fixo básico, seja efetivado no CRAS seja em outras unidades operacionais da assistência social do município, onde também são ofertados outros serviços complementares de proteção social básica, nos quais se trabalham com as famílias dos segmentos atendidos ou em grupos de famílias.

As normas técnicas (BRASIL, 2006, p. 42) definem os núcleos socioeducativos como espaço de discussão, vivências e reflexões, e há indicação para a abordagem de questões relacionadas às etapas dos ciclos de vida familiar. Sugere-se:

1 Criar situações em que as famílias possam expressar coletivamente suas dúvidas e conflitos, construindo soluções para os problemas cotidianos, relacionados ao cuidado de suas crianças, adolescentes, jovens, adultos, idosos e pessoas com deficiência.

2 Refletir com a família sobre as mudanças em sua dinâmica e redistribuição de papéis, a partir do desenvolvimento de seus filhos. Desenvolver habilidades de cuidado, orientação e acompanhamento das crianças. Debater aspectos relacionados ao desenvolvimento infantil, às necessidades de estimulação nessa fase da vida, à importância de proporcionar espaços e oportunidades voltadas e orientadas pelas necessidades infantis e desafiadoras [...]. Debater temas relacionados ao desenvolvimento da criança, do adolescente e do jovem, características e interesses.

3 Refletir sobre a necessidade de proteção aos seus membros idosos e de valorização do seu saber.

4 Discutir as estratégias para o desenvolvimento das competências da pessoa com deficiência, destacando o papel fundamental das famílias e da comunidade no processo de reabilitação e inclusão das pessoas com deficiências.

Estas sugestões dão a nítida dimensão do trabalho socioeducativo; ele se volta majoritariamente para a discussão de questões internas à família, no sentido de gerar habilidades para o cuidado doméstico, para o reforço das responsabilidades familiares, a partir dos novos conhecimentos adquiridos e da discussão e reflexão do seu cotidiano. Portanto, tais práticas são herdeiras da educação disciplinadora e normatizadora da família, que assumem versões modernizadoras que escamoteiam sua dimensão 
normativa, em nome de processos educativos que visam aquisição, junto à família, de novos conhecimentos, atitudes, posturas e poder de decisão, ou seja, sua "autonomia".

Essas recomendações materializam a noção de matricialidade sociofamiliar definidas na política e nas orientações de sua implementação e vice-versa, esta orienta o trabalho social com famílias; ambos não poderão superar, pelas suas limitações conceituais e práticas, as históricas tendências do modo de trabalhar com famílias, como a perspectiva psicologizante individual. Assim, a grande inovação do conceito de família subjacente à legislação não encontra formas de materialização. Admite-se a pluralidade de arranjos familiares, mas os trata como homogêneos em necessidades e em funções.

Apesar de essas recomendações incorrerem em uma dimensão conservadora do trabalho com famílias, verifica-se a potencialidade do trabalho social nos CRAS, em especial, com grupos, como antídoto à sua transformação em serviço cartorial, de cadastramento, recadastramento, acesso a benefícios, mas de oferta de serviços de suporte à família, que envolve a família e seus representantes com serviços de orientação, informação, conscientização sobre direitos, modos de acessá-los e garanti-los, e reflexão sobre suas dificuldades cotidianas.

Podem-se destacar também como inovadores os objetivos do trabalho social na proteção social básica, de fortalecer os vínculos familiares antes de sua dissolução, trabalhar de forma preventiva para evitar riscos e violação de direitos, por meio dos benefícios, programas e trabalho socioeducativo, que visam a autonomia e o protagonismo desses sujeitos. Contudo, em pesquisa realizada junto aos assistentes sociais com função técnica de gerência, responsáveis pelo gerenciamento e coordenação dos programas, projetos da Proteção Social Básica da Secretaria Municipal de LondrinaParaná, Carloto (2008) observou que esses termos - autonomia, empoderamento, protagonismo, emancipação - são ainda trabalhados de forma muito abstrata, e dificilmente são alcançados nos marcos de programas específicos.

É preciso superar a noção de autonomia, protagonismo social, empoderamento e outras expressões tomadas no aspecto individual, que se constroem pelo aconselhamento individual ou grupal, centradas na mudança da subjetividade individual ou do grupo, como forma de libertá-lo da dependência dos benefícios sociais, de ensinálo a "andar com as próprias pernas", mediante processos profissionais que fortalecem a 
autoestima, a capacidade produtiva, dando-Ihe condições de empregabilidade, como se a ausência de trabalho se devesse apenas a não capacitação ou falta de vontade, de crença nas suas potencialidades.

A noção de autonomia como a capacidade de cada sujeito dar conta de sua vida, dos cuidados necessários para que ele caminhe sem a necessidade de benefícios sociais, de aconselhamento e acompanhamentos pode induzi-lo a buscar saídas nele mesmo, em suas capacidades, potencialidades, inclusive do reforço de suas responsabilidades familiares e individuais, e não na luta pelo beneficio como um direito, inclusive, universal, como dever do Estado de prover certo padrão digno de vida a todo cidadão, cujas condições são reflexos das desigualdades e que afetam as relações familiares.

É preciso direcionar o trabalho socioeducativo com famílias para além dessa dimensão liberal, individual e subjetivista de autonomia, no sentido de articular significados e práticas; ou seja, partir da compreensão de que as subjetividades se alteram pelas práticas sociais e não por simples conscientização. Daí ser fundamental o acesso a condições objetivas, fornecidas pelas políticas públicas como direitos. Nisso se incluem a apropriação e produção de novos sentidos pessoais e a inserção da pessoa no engajamento coletivo por melhores condições de vida (KAHHALE, 2004), de modo que é indispensável o processo de informação, reflexão, mas também de organização dos diferentes grupos que compõem o território para que seus direitos sejam garantidos e novas conquistas sejam inseridas nas políticas públicas, a partir de suas demandas.

Assim, a constituição de sujeitos de direitos se dá no processo de compreensão das determinações sociais de suas condições de vida, material e afetiva; no reconhecimento da força do coletivo; e nas possibilidades concretas de acesso aos bens e serviços produzidos socialmente.

\section{Trabalho social com famílias: elementos para sua reconstrução em bases críticas}

Entre os novos pressupostos para o trabalho social com família, destaca-se a concepção de família. Para a compreensão ampla do termo e que dê conta da variedade de organizações familiares, é preciso analisá-la não como uma instituição natural, mas social e histórica, podendo assumir configurações diversificadas em sociedades ou no interior de uma mesma sociedade, conforme as classes e grupos sociais heterogêneos. 
Para Mioto (1997, p. 116), essa compreensão "se contrapõe ao entendimento de que a família é um grupo natural, limitado à essência biológica do homem e à sua continuidade através da consanguinidade e da filiação", assim como da naturalização da divisão sexual do trabalho, dos papéis, da identificação do grupo conjugal como forma básica elementar de toda família, dentre outras.

O segundo passo é romper com as concepções que tratam a família como interiormente homogênea e apreciável em qualquer contexto social e histórico (SARACENO, 1992). Os estudos antropológicos têm apontado uma variedade de experiências familiares ao longo da história e na contemporaneidade, modos de organizações plurais, $^{2}$ assim como modos diferentes de atribuir significados aos agrupamentos familiares. Conforme destaca Saraceno (1992, p. 210), “as famílias realmente existentes não são de modo nenhum homogêneas entre si no que diz respeito a recursos, fase do ciclo de vida, mas também modelos culturais e organizativos".

Também internamente, a família não é homogênea, as relações entre seus membros são assimétricas, conservam diferenciações de gênero e de geração, e são hierarquizadas. Não se trata de um bloco homogêneo nem necessariamente harmonioso (SARACENO, 1992; CAMPOS, 2008).

O termo unitário família alude a uma forte unidade e homogeneidade, porém oculta uma realidade marcada por interesses divergentes, modelos hierárquicos, relações de poder e força, mas também processos de negociação, de cooperação e de solidariedade. Saraceno (1992, p. 14) afirma que a família também é o espaço histórico e simbólico no qual e a partir do qual se desenvolve a divisão do trabalho, dos espaços, das

\footnotetext{
${ }^{2}$ De acordo com Szumanski (2002), podemos distinguir nove tipos de composição familiar ou de família na contemporaneidade: 1) Família Nuclear: são as famílias formadas por pai, mãe e filhos biológicos, ou seja, é a família formada por apenas duas gerações; 2) Famílias Extensas: são as famílias formadas por pai, mãe, filhos, avós e netos ou outros parentes, isto é, a família formada por três ou quatro gerações; 3) Famílias Adotivas Temporárias: são famílias (nuclear, extensa ou qualquer outra) que adquirem uma característica nova ao acolher um novo membro, mas temporariamente; 4) Famílias Adotivas: são as famílias formadas por pessoas que, por diversos motivos, acolhem novos membros, geralmente crianças, que podem ser multiculturais ou birraciais; 5) Famílias de Casais: são as famílias formadas apenas pelo casal sem filhos; 6) Famílias Monoparentais: são as famílias chefiadas só pelo pai ou só pela mãe; 7) Famílias de casais homossexuais com ou sem criança: são as famílias formadas por pessoas do mesmo sexo, vivendo maritalmente, possuindo ou não crianças; 8) Famílias reconstruídas após o divórcio: são famílias formadas por pessoas (apenas um ou o casal) que foram casadas, que podem ou não ter crianças do outro casamento; 9) Famílias de várias pessoas vivendo juntas, sem laços legais, mas com forte compromisso mútuo: são famílias formadas por pessoas que moram juntas e que, mesmo sem ter a consanguinidade, são ligadas fortemente por laços afetivos.
} 
competências, dos valores, dos destinos de homens e mulheres, ainda que isso assuma formas diversas nas várias sociedades.

Considerando essa diversidade, a família pode ser definida "como um núcleo de pessoas que convivem em determinado lugar, durante um lapso de tempo mais ou menos longo e que se acham unidas, ou não, por laços consanguíneos" (MIOTO, 1997, p.120); ou ainda, como destaca a autora: "estamos diante de uma família quando encontramos um espaço constituído de pessoas que se empenhem umas com as outras, de modo contínuo, estável e não-casual [...] quando subsiste um empenho real entre as diversas gerações" (MIOTO, 2004a, p. 14-15).

Trata-se de uma visão ampliada e atual de família, posto que as pessoas que convivem em uma ligação afetiva duradoura podem ser um homem e uma mulher e seus filhos biológicos; mas também um casal do mesmo sexo, ou apenas a mulher com seus filhos legítimos ou adotados, e outra infinidade de arranjos.

O que dá unidade a essa síntese de múltiplas determinações que permite usar o termo família, apesar da diversidade que a comporta, da pluralidade de formas, experiências e significados é o fato de esta ser (MIOTO, 2000, p. 1) o espaço privilegiado da história da humanidade, no qual aprendemos a ser e a conviver; ou seja, ela é a matriz da identidade individual e social, portanto, geradora de formas comunitárias de vida e espaços de proteção primária aos seus membros.

Essa concepção, portanto, contrapõe-se àquelas concepções que: - tratam a família a partir de uma determinada estrutura, tomada como ideal (casal com seus filhos) e com papéis predefinidos; - tomam a família como a principal responsável pelo bem-estar de seus membros, desconsiderando em grande medida as mudanças ocorridas na sociedade (MIOTO, 2010).

A partir desse eixo alternativo, as necessidades trazidas por sujeitos singulares não mais são compreendidas como problemas individuais/familiares, ou tratados como casos de famílias. Segundo Mioto (2004b, p.12), as "condutas, dificuldades e problemas expressos pelas famílias são interpretados como expressão de conflitos instaurados no contexto de uma dinâmica familiar [...] profundamente marcada pelas contradições de uma sociedade em um determinado momento histórico". Nessa perspectiva, o trabalho socioeducativo com famílias ultrapassa a indução de reflexões internas e o uso do grupo 
como troca de experiências e ajuda mútua, para se transformar em instrumento de construção de um novo conhecimento, partilhado e crítico, que os leva a sair do imediatismo de suas necessidades, para entendê-las enquanto coletivas, enquanto necessidades sociais de classe, que devem ser atendidas pelo poder público, como condição fundamental para a garantia de direitos e de qualidade de vida.

O que não significa que os temas relacionados às vivências, sofrimentos, violências, decorrentes da situação de vulnerabilidade ou risco social que compartilham não sejam debatidos, refletidos, mas deve-se evitar o que Sawaya (2004) denomina "ditadura da intimidade" ou "ditadura da privacidade", que expressa o fortalecimento da família apartheid, pois isola seus membros de outras formas de associação e grupos, fechando temas de interesse no espaço doméstico e a cargo das famílias.

Esse fechamento da família em si mesma e nas soluções domésticas aumentaria o sofrimento de não poder cumprir os papéis sociais exigidos por ela, como, por exemplo, tirar os filhos da rua, da criminalidade, da delinquência, das drogas, além de dar sustentabilidade material, afetiva, proteção e cuidados a seus membros, sem compreender o porquê da redução de seu poder e autoridade perante as gerações mais jovens, da redução do tempo dedicado ao lar, do endurecimento das relações afetivas e até da violência no seio familiar.

Nessa perspectiva, o foco das ações socioassistenciais e socioeducativas deve ser as necessidades das famílias e a garantia dos direitos de cidadania, cujas propostas e ações perpassam o âmbito específico de uma política, para uma perspectiva intersetorial, integrada e articulada. No âmbito específico da assistência social, essas ações devem ser guiadas pela efetivação de direitos e da responsabilidade pública, que deve ser o norte do trabalho social com famílias ou grupos de famílias.

Os objetivos do trabalho social com famílias devem ser a autonomia e o protagonismo, compreendidos na perspectiva de participação social e do coletivo. Assim, é essencial superar a visão liberal de autonomia, do "ensinar a pescar", do "andar com suas próprias pernas" sem que seja garantido como direito o acesso às condições materiais e subjetivas necessárias para tal. Para superar essa dimensão individualista do conceito de autonomia, Kahhale (2004, p. 105) sugere a sua complementação com o 
conceito de cidadania, que indica acesso a direitos e participação ativa nos rumos da sociedade, utilizando o conceito de Sposati (2004, p. 04), que considera cidadania como:

\begin{abstract}
O reconhecimento de acesso a um conjunto de condições básicas para que a identidade do morador de um lugar se construa pela dignidade, solidariedade [...]. Esta dignidade supõe não só o usufruto de um padrão básico de vida, com a condição de presença, interferência e decisão na esfera pública da vida coletiva.
\end{abstract}

Nessa perspectiva, o trabalho socioeducativo em grupo se encaminha para o reconhecimento das famílias e seus membros como sujeitos de direitos. A pessoa participante do grupo de famílias é levada a ver-se como representante de uma família, cujos problemas vivenciados são comuns a muitas outras famílias que sofrem as mesmas determinações, e que participa de um grupo maior com situações semelhantes. O grupo deve se enxergar enquanto tal, identificar e encaminhar demandas e visualizar suas possíveis soluções, como ainda superar a responsabilização individual pelo bem-estar social, para incluir a dimensão pública e social destas, mediante articulação de serviços e políticas que promovam a proteção social.

Acredita-se que, com essa perspectiva, se ultrapasse a noção de subjetividade individual para a dimensão coletiva, e se promova a organização social, a participação popular, e a passagem da necessidade ao direito, como possibilidades concretas de construção de novos significados e práticas, inclusive a de sujeitos de direitos.

Assim, a autonomia como capacidade de decidir, optar, eleger objetivos, metas, crenças é condição fundamental para que se alcancem objetivos de participação social, principalmente, para o reconhecimento da força do grupo, da organização e lutas coletivas.

A noção de autonomia das famílias não se deve restringir à busca de respostas e soluções dos problemas por si mesmas, em especial, mediante recursos internos; antes, implica o desenvolvimento da capacidade de discernir as mudanças possíveis de serem realizadas no âmbito dos grupos familiares e de suas redes daquelas que exigem o engajamento deles, organizados em coletivos, em processos sociais mais amplos para que ocorram transformações mais gerais e a efetivação de direitos. Assim, envolve capacidade de opinar, escolher, decidir e agir intencionalmente, mediante suportes oferecidos, 
capacidades construídas, situações refletidas, informadas, debatidas, devendo ser esses os objetivos da educação que visa a emancipação.

Para efetivar essas potencialidades, é preciso ainda superar o trabalho socioeducativo em grupo como espaço terapêutico, clínico, de tratamento pela troca de experiências comuns.

O trabalho socioeducativo com grupos de famílias, ou grupos de segmentos atendidos, que algumas vezes envolve suas famílias, funciona como espaço de reflexão e troca de experiências, utilizado em muitas situações como um recurso terapêutico, cuja direção do que é discutido e refletido se encaminha, predominantemente, para questões internas às famílias, seus conflitos, como exercer seus papéis, ou empregado para prestar informações.

Esse reducionismo das funções socioeducativas pode fortalecer práticas normativas e disciplinadoras que se dirigem a ensinar as famílias a gerir recursos, a disciplinar os filhos, a exercer as funções de cuidado, proteção e educação, sem alterar as situações que as impedem de exercê-las como há cinquenta anos. É preciso compreender as mudanças, inclusive de valores, culturais e sociais sobre a família, e buscar estratégias de como conviver com elas, a partir, principalmente, do apoio do poder público, da rede social com acesso igualitário de oportunidades e aos recursos públicos e privados.

Apesar das mudanças que o termo terapia tem passado, ainda significa "tratamento de doença, desordem, defeito etc., por algum tipo de processo curativo ou que remedie" (PENGUIN apud CAMPOS; REIS, 2009, p. 60); seu uso é, portanto, inapropriado para a proteção social básica, seja individual ou coletiva.

Sem dúvida, o grupo é um espaço de potencialidades, em que se realizam a escuta, a reflexão, o diálogo e a troca de experiências; um espaço de comunicação e aprendizagem ( $C f$. GUIMARÃES; ALMEIDA, 2007, p. 132). Todavia, não deve ser utilizado como instrumento de busca de enfrentamento das situações de carência de modo individualizado nem por meio dos recursos da família e da comunidade, eximindo o poder público da responsabilidade pelo enfrentamento da questão social, nem responsabilizando as famílias pela busca de soluções de problemas que extrapolam suas possibilidades de respostas, nem com fins terapêuticos e subjetivistas. 
O trabalho socioeducativo é cada vez mais necessário, visto que, na expressão de Mioto (2004b), a cidadania não se restringe ao acesso a benefício monetário, embora sua inclusão como beneficiário seja uma das condições para sua realização, mas a cidadania envolve também ações em direção à informação, à educação, à cultura, entre outras, implicando o desenvolvimento da capacidade de refletir, de analisar, de decidir, de mobilizar-se e de participar pelo bem comum. Contudo, para cumprir essa dimensão educativa em uma perspectiva emancipatória, não se deve restringir a responsabilizar as famílias, ou a ensiná-las a gerir seus conflitos, seus parcos recursos, sua vida, como se tudo dependesse de um processo de racionalização e planejamento, de cumprimento de papéis e normas e não de carências coletivas. Logo, deve-se evitar essa dimensão disciplinadora e levar as famílias a refletirem sobre sua realidade, conhecer serviços e recursos do território, mobilizar-se e incluir-se em processos organizativos, coletivos, na busca de garantia dos seus direitos.

Os objetivos do trabalho socioeducativo devem ser o fortalecimento do processo organizativo dos usuários, do coletivo; do desenvolvimento do sentimento comum na família, nos grupos de família, naquele território; a necessidade da participação e do controle social. Algo que se aproxima de uma educação que visa a emancipação social. Logo, o oposto às recomendações do MDS e as dimensões da noção de matricialidade sociofamiliar, incapazes de superar a subalternidade histórica dos usuários da assistência social.

Os processos de escuta qualificada, de acolhimento, de acompanhamento não devem ser compreendidos como terapêuticos nem domínios da Psicologia, mas modos de trato do usuário como cidadão, como sujeito de direito, o direito a ter atendimento respeitoso, atencioso, que informa, orienta, acolhe e escuta.

As alternativas metodológicas devem ser pensadas e executadas, buscando superar a dicotomia entre assuntos interno e externo à família, sem hipertrofiar um em detrimento do outro, mas trabalhar sua dialética, entendendo o interno não fechado nos muros domésticos, mas decorrentes da estruturação da sociedade e de suas dinâmicas de transformações, e a necessidade do fortalecimento do coletivo na luta pela garantia de respostas públicas às suas necessidades. 
Guimarães (2004, p. 115) salienta os passos metodológicos do trabalho socioeducativo com famílias:

São acolhidas e consideradas as dúvidas, os problemas, as preocupações e o sofrimento trazido pelos integrantes do grupo. Ao mesmo tempo, procura-se auxiliar o participante e o conjunto das pessoas a situarem a questão em seu contexto social mais amplo, informando, debatendo, orientando a discussão para a compreensão do que é vivido e sofrido subjetivamente, articulado ao contexto mais amplo e comum aos membros do grupo: os direitos do cidadão.

Essas estratégias metodológicas poderão contribuir para a construção de propostas de trabalho comprometidas com a lógica do direito, da construção de sujeitos sociais conscientes e participativos, sem negligenciar as preocupações imediatas das famílias, inclusive seus conflitos familiares, seus sofrimentos, mas sem cair no psicologismo dos problemas sociais.

Trabalhar dialeticamente as questões internas e externas às famílias, de forma articulada e numa perspectiva de totalidade, como recomendação de "não dar à questão social um tratamento de exterioridade à vida pessoal cotidiana" (SAWAYA, apud CAMPOS, 2004, p. 33), mas sem supervalorizar as questões subjetivas ou internas às famílias, cujo objetivo deve ser sempre o alargamento da percepção das situações pessoais e sociais e a luta pela garantia dos direitos.

O trabalho socioeducativo com famílias ou grupos de famílias, bem como os procedimentos individuais de acolhimento, escuta qualificada, encaminhamentos e acompanhamentos devem buscar a inserção desses sujeitos no circuito do território e da rede de segurança social e articular o individual e o familiar no contexto social, levandoos a ultrapassar o imediatismo de suas concepções, mas tendo como princípio que subjetividades transformadas só provocam mudanças com ações coletivas, com acesso a serviços, benefícios, ou seja, com condições objetivas.

\section{Considerações Finais}

A centralidade na família e o trabalho social com famílias previsto no novo desenho da Política de Assistência Social podem significar avanço ou retrocesso, como o 
fechamento das análises e propostas de trabalho nos conflitos familiares, favorecendo o ocultamento das contradições da sociedade de classes, na medida em que suas reflexões ficam restritas em análises da família nela mesma ou no território, dissociadas da realidade mais ampla, como também num trabalho psicossocial e educativo de caráter normativo e disciplinador, fundamentados em pressupostos sexistas dos papéis sociais e do poder deste de disciplinar, gerar socializações menos rebeldes, impor limites, controlar desvios diversos.

As possibilidades de superação dessa tradição histórica do trabalho social com famílias passam pelo desafio da ruptura com as concepções de família-padrão, família irregular, e pela utilização de metodologia de trabalho com famílias que, de fato, abordem de forma dialética e articulada, assuntos internos e externos à família, sem hipertrofiar um dos polos e sem cair em modelos psicossociais individualizantes ou seu oposto os generalistas de transformação social, sem soluções práticas para o dia a dia.

Está na ordem do dia pensar metodologias de trabalho com famílias que articulem a dialética entre questões internas e de protagonismo social, questões objetivas e subjetivas da vida social e das famílias. Mas cuja direção deve superar as questões meramente internas, ou articulá-las ao contexto de desigualdade e exclusão social, às transformações sociais e culturais e à necessidade de lutas coletivas para conquista e garantia de direitos, e de controle social das políticas públicas dirigidas as suas necessidades.

Outro desfio é a não responsabilização da família pelos problemas e soluções destes ou a superestimação da capacidade de as famílias se autoproverem de cuidados, como sinônimo de autonomia, protagonismo, em que se ensina a estas "andarem pelas próprias pernas", usando seus recursos internos e da comunidade.

Em relação aos profissionais da equipe interdisciplinar, exige-se postura crítica que vise o protagonismo dos usuários, dentro do quadro das lutas por seus direitos de cidadania concomitantemente ao de suas relações familiares; portanto, devem ser garantidos pelo poder público, em quantidade e qualidade, para atender suas necessidades, além de abertura para a realidade social para além do grupo familiar e realidade do território, tanto na análise da realidade e dos problemas como na intervenção para resolvê-los. 
Por fim, atuar na direção do enfrentamento cotidiano por direitos das famílias e seus membros, mediante o encorajamento de sua participação social; trabalhar em uma perspectiva de ampliação do universo informacional e permitir a identificação de recursos no território, na cidade, no âmbito das diversas políticas, de forma a buscar a inserção das pessoas e famílias na rede de segurança social.

\section{Referências}

BRASIL. Ministério do Desenvolvimento Social e Combate à Fome. Lei Orgânica da Assistência Social (PNAS). Brasília: MDS\SNAS, 1993.

BRASIL. Ministério do Desenvolvimento Social e Combate à Fome. Política Nacional de Assistência Social (PNAS). Brasília: MDS\SNAS, 2004.

. Ministério do Desenvolvimento Social e Combate à Fome. Norma Operacional Básica da Assistência Social (NOB\SUAS). Brasília: MDS\SNAS, 2005.

Ministério do Desenvolvimento Social e Combate à Fome. Proteção Básica do Sistema Único de Assistência Social: orientações técnicas para os Centros de Referência de Assistência Social. Brasília: MDS\SNAS, 2006.

CAMPOS, M. S. Possibilidades abertas pelp Programa Fortalecendo a Família - PFF/SP/SP. In: WANDERLEY, M. B; OLIVEIRA, I. C. (Org.). Trabalho com famílias: textos de apoio, v. 2, São Paulo: IEE-PUC-SP, 2004.

. Família e Proteção social: alcances e limites. In: ZOLA, M. B. (Org.). Cooperação internacional para proteção de crianças e adolescentes: o direito à convivência familiar e comunitária. São Bernardo do Campo-SP: Fundação Criança de São Bernardo do Campo, 2008.

; REIS, D. S. Metodologias do trabalho social no CRAS. In: CRAS: marcos legais. São Paulo: Prefeitura Municipal de São Paulo, 2009.

CARLOTO, C. M. A política de Assistência Social e a centralidade na família: desafios e impasses no processo de operacionalização. In: ENCONTRO NACIONAL DE PESQUISADORES EM SERVIÇO SOCIAL, IX. São Luis: ABEPSS, 2008.

ESPING-ANDERSEN, G. Social foundations of posindustrial economies. New York: Oxford, 1999.

FONTENELE, I. C. O controle da pobreza na ordem do capital: a centralidade da assistência social no Brasil do ajuste neoliberal. Tese (Doutorado em Políticas Públicas) - UFMA, São Luís, 2007.

GUIMARÃES, C. H. O trabalho socioeducativo sob o olhar da Psicologia. In: WANDERLEY, M. B; OLIVEIRA, I. C. (Org.). Trabalho com famílias: textos de apoio, v.2, São Paulo: IEEPUC-SP, 2004. 
GUIMARÃES, R. F.; ALMEIDA, S.C.G. Reflexões sobre o trabalho social com famílias. In: ACOSTA, A. R.; VITALE, M. A. F. (Org.). Família: redes, laços e políticas públicas. 3. ed. São Paulo: Cortez\PUC-SP-IEE, 2007.

KAHHALE, E. M. P. Subjetividade e transformação social. In: WANDERLEY, M. B; OLIVEIRA, I. C. (Org.). Trabalho com famílias: textos de apoio, v.2, São Paulo: IEE-PUC-SP, 2004.

MIOTO, R. C. T. Família e serviço social: contribuição para o debate. Serviço Social e Sociedade. São Paulo: Cortez, n.55, p.115-130, 1997.

. Cuidados sociais dirigidos à família e segmentos sociais vulneráveis. In:

CONSELHO FEDERAL DE SERVIÇO SOCIAL. O trabalho do assistente social e as políticas sociais, mod. 04, Brasília, UnB, CEAD, 2000.

. O trabalho com redes como procedimento de intervenção profissional: o desafio da requalificação dos serviços. Revista Katálysis, v. 5, n.1, p.51-58. Florianópolis-SC, 2002.

. "Que família é essa" In: WANDERLEY, M. B; OLIVEIRA, I. C. (Org.). Trabalho com famílias: textos de apoio. v. 2. São Paulo: IEE-PUC-SP, 2004a.

Ações socioeducativas em programa de transferência de renda. In: WANDERLEY, M. B; OLIVEIRA, I. C. (Org.). Trabalho com famílias: textos de apoio. v.2. São Paulo: IEEPUC-SP, 2004b.

Novas propostas e velhos princípios: a assistência às famílias no contexto de programas de orientação e apoio sociofamiliar. In: SALES, M. A.; MATOS, M. C. de; LEAL, M. C. (Org.). Política social, família e juventude: uma questão de direitos. 2. ed. São Paulo: Cortez, 2006.

. Família, trabalho com família e Serviço Social. Serviço Social em Revista, Londrina, v.12, n.2, p. 163-176, 2010.

SANTOS, W.G. dos. Cidadania e justiça: a política social na ordem brasileira. Rio de Janeiro: Campus, 1987.

SARACENO, C. Sociologia da família. Lisboa: Estampa, 1992.

SAWAYA, B. B. Que família é essa" In: WANDERLEY, M. B; OLIVEIRA, I. C. (Org.). Trabalho com famílias: textos de apoio, v. 2, São Paulo: IEE-PUC-SP, 2004.

SPOSATI, A. A especificidade e intersetorialidade da política de assistência social. Serviço Social e Sociedade. São Paulo: Cortez, n. 77, ano XXV, p. 30-62, 2004.

SZUMANKI, H. Viver em família como experiência de cuidado mútuo: desafio de um mundo em mudanças. Serviço Social e Sociedade. São Paulo: Cortez, n. 71, p. 9-25, 2002.

Recebido em: 30/07/2010

Aprovado em: 25/08/2010 